\title{
Using GIS for Assessment of Terrorists Attack Risk Along a Major Road and to Propose Security Options
}

\author{
W. G. Sumathipala and N. T. S. Wijesekera
}

\begin{abstract}
In Colombo and its suburbs, the risks of terrorist attacks are increasing day by day. The risk of civilians coining under attack is greater in areas that are with a greater presence of key decision makers. Therefore, in each of such locations the government has an obligation to assess the associated risk and then to facilitate with sufficient security to ensure civilian safety at least during the presence of key decision makers.
\end{abstract}

The parliament road from the Colombo Fort passing Kollupitiya and reaching the parliament at Sri Jayewardenepura can be considered as a major road that faces a significant risk due to the frequent presence of important decision inakers. Hence it is necessary to identify the risk factors associated with the parliament road. GIS provides a significant advantage when assessing the risk ratings of an associated geographic area and then identifying a suitable security system for public safety.

The present work describes the terrorists attack risk status along the parliament road determined through a simple GIS overlay model. The project area covers a road length on $12 \mathrm{~km}$. Data used for the GIS model were 1:50,000 maps of roads, GN boundaries, Land use, Population, Previous Incidents, waterways Spatial distribution of risk indicators were overlaid with a conceptual security deployment. The present work has not considered the present deployment along the parliament road due to security reasons.

The GIS model demonstrates that it can be effectively used to plan and deploy security to ensure the safety of road users.

Key words: GIS Model, Security, Risk, Road Assessment

\subsection{Introduction}

Escalation of LTTE terrorist activities has forced the government to find ways to ensure the safety of the public, public representatives and public property. The brutal terrorist attacks in the country have created significant disturbances to civilian life. Though the communities all over the world denounce the attacks on innocent unarmed civilians, the civilians are the set who suffers and absorbs most of the damage. Civilian lives are more at risk when they are among key decision makers and public representatives. In most occasions the general public are forced to be with the decision makers or are forced to attend meetings of public representatives. As a result such situations become unsafe for the public. It is well understood that anywhere in the world terrorists would attack common types of infrastructure and these have been well documented. Roads, Key Government Establishments, Officer Residences and Public Meetings are some of the common targets [7,
10]. During the history of separatist war, Sri Lanka has lost many of the leading public representatives due to terrorist attacks. The incidents have been either along main roads or at public rallies. When safety of the general public is concerned, locations that encounters the presence of general public along with Key Decision makers fall into top priority area category where risk assessments should be performed. As a result, in case of such locations, the government has an obligation to assess associated risk and facilitate sufficient security at least during the time periods when key decision makers are present.

Road coded as ASP which links parliament complex of Sri Lanka to the core of Colombo

W.G Sunathipala, Geographic Information for Strategic Defence Applications, Centre for Research \& Develomment, Ministry of Public Administration, Defence, Law and Order, Army Cantonment, Panagoda, Honagama, Sri Lanka

Eng. (Prof.) N.T, Sohan Wijesekera B.Sc.Eng. Hons.(Sri Lanka), PG.Dip (Moratuwa), M.Eng.(Tokyo),D.Eng. (Tokyo), MICE(UK), FIE(SL), Chartered Civil Enginecr, Department of Civil Engineering, Universityof Moratuwa, Katubedda, Moratuwa, Sri Lanka. 
Municipality area is frequently used by Public representatives and important Government Officials. This road links many residential areas to public facilities and commercial establishments. The parliament of Sri Lanka or the National State Assembly is the central meeting place for Key decision makers of the country. His Excellency the President is the leader of the Nation and the Presidential secretariat which coordinates the actions of the President is linked to the Parliament by this main Road. As a result, this road is very commonly used by the Public Representatives, Heads of Departments and Other government officials. This road is the main link for the persons in Residential Areas of Battaramulla, Kaduwela, Malambe, and Kotte to reach Colombo Municipality area where the popular schools, main hospitals, most government offices and vast commercial activities are located. This road is an alternative to reach Borella for those who use Kandy Colombo A-1 road. High-level road (A-4) users also deviate at Meepe to join this road to avoid traffic congestion at Maharagama, Nugegoda etc. Therefore, considering the criticality of $a$ terrorist attack, this road could be considered as a priority location for a risk assessment.

Risk management of this road requires the assessment of many factors which are spatially distributed. Hence it involves decision making based on map referenced information. Geographic Information Systems are excellent tools for decision making with the use of models involving several map overlays. [5, 4]

Effective capability to use GIS for such risk assessments would be of immense importance for the government to provide public security. This has been emphasized in literature $[3,10]$. Therefore, the present work describes an application indicating the potential use of GIS for risk assessment in a spatially distributed manner using the important parliament (ASP) road as a case study. The work also indicates the possibility of incorporating the security strengths to ensure public safety. Since the potential of using GIS efficiently will be a very important factor for the assessment of public security in other areas as well, this study would be an important contribution to public safety.

\subsection{Study Area}

The study area is a spatial extent of approximately $32 \mathrm{~km}^{2}$, consisting of 33 Grama Niladari Divisions (GND) in the Colombo and Sri Jayewardenepura jurisdictions, falling within 60 52I and 60 57I North Latitudes and within 790 50I and 790 56I East Longitudes. Road which is popularly known as the Parliament Road reins from Kollupitiya to National State Assembly of Sri Lanka (located at Battaramulla) and is officially labelled as ASP road (survey 1989).

The study which looked at the security for the access from the Colombo city to National State Assembly (NSA), selected a link road from Colombo Fort to ASP near Kollupitiya and the balance of ASP as the road for the study (Figure 1). The road sections selected for the assessment crosses the baseline road at approximately half way. Total length of road selected for the case study is $12 \mathrm{~km}$. The study which targeted to assess the risk status at least to a distance of $400 \mathrm{~m}$ from the road, selected the Grama Niladari Divisions (GND) covering the minimum distance of $400 \mathrm{~m}$, as the spatial coverage for GIS Model. Considering reasons of administrative convenience, the full extent of each GND was chosen of the study. Land use of the study area mainly consisted of Homesteads - $17.77 \mathrm{~km} 2$ (55. \%), Built-up Area - $6.49 \mathrm{~km} 2$ (20. $\%$ ), and Water - $6.73 \mathrm{~km} 2$ (21. \%). Land cover distribution details for the study area is in Table1 Road coverage of the study area consists of $12 \%$ main roads, $84 \%$ minor roads and $4 \%$ of cart or jeep tracks. Table2.

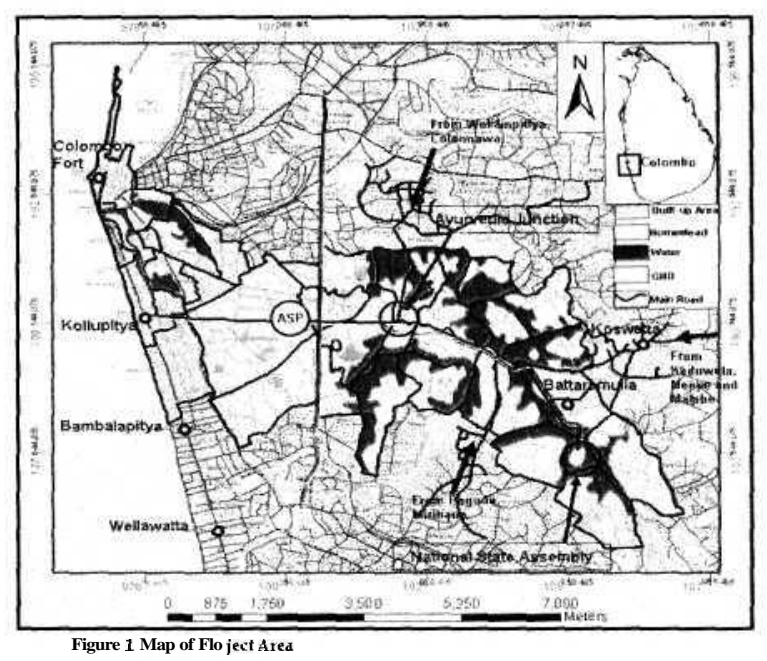

Figure 1 : Map of Project Area 
Table 1: Land use Distribution of Study Area

\begin{tabular}{|ll|c|c|}
\hline & Description & Area(sqkm) & Percentage \\
\hline 1 & Homestead & 17.77 & $55.18 \%$ \\
2 & Built-up Area & 6.49 & $20.14 \%$ \\
3 & Grass Land & 0.57 & $1.75 \%$ \\
4 & Paddy & 0.58 & $1.80 \%$ \\
5 & Rubber & 0.01 & $0.05 \%$ \\
6 & Water \& Marsh & 6.73 & $20.9 \%$ \\
7 & Bay, Sea, Sand & 0.06 & $0.18 \%$ \\
& Total & 32.21 & $100 \%$ \\
\hline
\end{tabular}

Table 2 : Roads Distribution of Study Area

\begin{tabular}{|ll|c|c|}
\hline Description & $\begin{array}{c}\text { Road } \\
\text { Length km }\end{array}$ & Percentage \\
\hline $\mathbf{1}$ & Main road & 41.06 & $12 \%$ \\
$\mathbf{2}$ & Minor road & 290.76 & $84 \%$ \\
$\mathbf{3}$ & Jeep or Cart track & 16.41 & $4 \%$ \\
& Total & 348.24 & $100 \%$ \\
\hline
\end{tabular}

\subsection{Objective}

Objective of the work is to demonstrate the potential of GIS to assess the terrorist attack risk along a major road which is selected as the parliament road and to incorporate security options in a systematic manner, thereby enabling the effective use of GIS for security related operation.

\subsection{Methodology}

Risk is a function of assets, threats and vulnerabilities. Risk is described as the potential for an unwanted event to occur due to actions of terrorists. Terrorist threat is the capability and intention of an adversary to undertake actions that are detrimental to the government. Vulnerability is any weakness in an asset or counter measure that can be exploited by a terrorist to cause damage to the government. In risk assessment, a criticality of an asset which is an evaluation of the relative importance of an asset within a jurisdiction is the foremost task. A terrorist risk assessment combines criticality, threat and vulnerability and is summarized in to a risk status as given in the following [10].

\section{Risk $=$ Threat $\mathrm{x}$ Vulnerability $\mathrm{x}$ Criticality}

In the present work, the selection of parliament road for the study embeds an initial evaluation of criticality which had concluded on the location by considering the traffic that is associated with the road, the concerns with respect to the, National State Assembly, the movement of public Representatives, the link to city centre etc.

Similarly on assessment of the threat component for the work had also been taken care of by clearly identifying the parliament road as an asset that creates a very high threat to Public and Public- representatives once the terrorist capabilities, intentions, and tactics are carefully considered. Therefore, for the parliament road, of which the criticality and the threat had been prioritized, a vulnerability assessment would reflect the risk assessment. Such assessment need to incorporate the identification of weaknesses in physical structures, protection systems, processes or and other areas that may be exploited by the terrorists. Therefore, the objective function for the assessment of spatial variability of terrorist attack risk associated with the parliament road identified that the key parameters are the road, link roads, land cover, population distribution, previous incidents, built-up area coverage and number of junctions. Parameter data layers were combined with administrative boundary data to enable identification of risk in relation to such divisions. A simple qualitative weighted overlay GIS model was developed to assess the risk in the spatial vicinity of parliament road (Figure2).

A questionnaire based user survey [9] was carried out to identify important data layers, same survey incorporated data capture fields that are necessary for the identification of spatial zoning with regards to influencing parameters. Map data collection, checking and computation were carried out as an initial task of model development. Data layers used for the study are

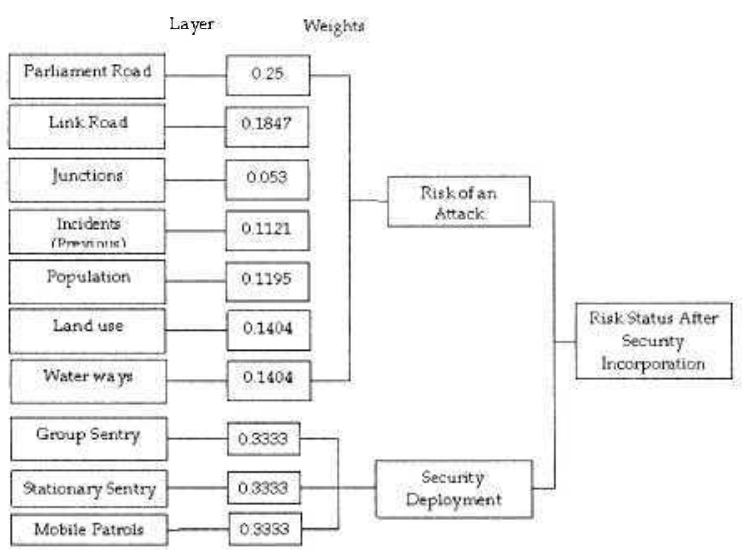

Figure 2 : GIS Overlay Model usedfor the Study 
Table 3: Data layers used for the study

\begin{tabular}{|c|c|c|c|}
\hline Data layer & Description & Layer type & Spatial zoning \\
\hline 1 Road & $\begin{array}{l}\text { Main, Miner, Jeep or Cart track, } \\
\text { 1:50,000 map }\end{array}$ & Poly Line & Buffering of Main and Link roads \\
\hline 2 Junctions & Major junctions from 1:50,000 map & Point & Buffering of intersections. \\
\hline 3 GND & $\begin{array}{l}\text { Total Population as Attributes } \\
\text { 1:50,000 }\end{array}$ & Polygon & Population Density \\
\hline 4 Land use & $\begin{array}{l}1: 50,000 \text { reclassified to groups } \\
\text { according to study objectives }\end{array}$ & Polygon & $\begin{array}{l}\text { Land use type to extract } \\
\text { Waterways and Built-up area, etc. }\end{array}$ \\
\hline 5 Waterways and Marsh & 1:50,000 land use & Polygon & Buffering of Waterways. \\
\hline 7 Previous Incidents & 1:50,000 Incidents Map & Point & Buffer of incidents \\
\hline
\end{tabular}

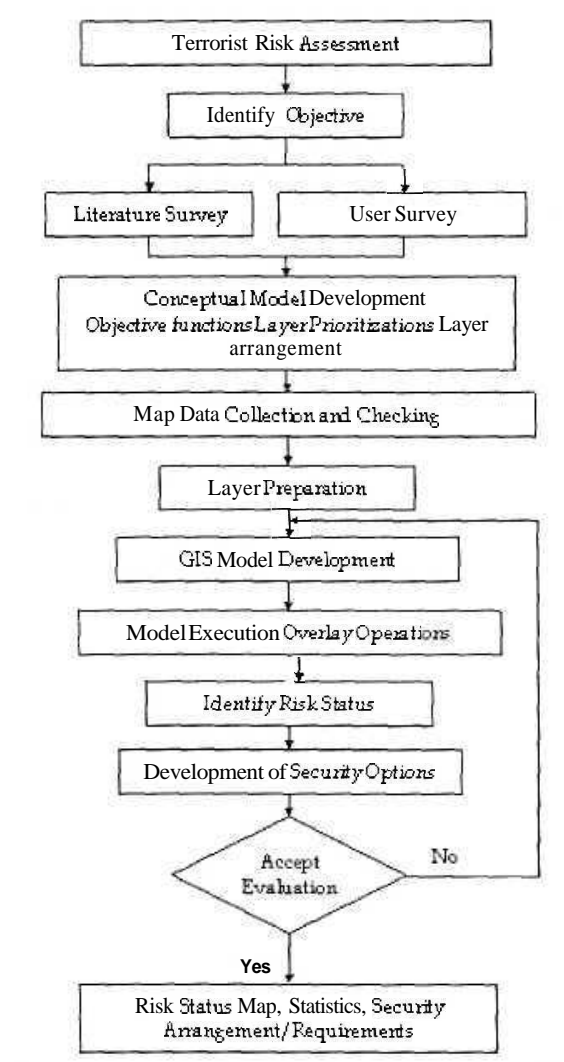

Figure 3 : Execution Methodology Flow Chart

shown in Table 3. Overall process flow chart of the execution methodology is shown in Figure 3.

Questionnaire survey which was carried out using a sample of educated stakeholders consisting 29 persons identified the distances pertaining to each feature Layer describing spatial zones with a five class hierarchical qualitative classification [9]. The distances were then regrouped using the frequency plots. Ranks and final parameters for the model were established from the use of frequency values and a trial and error method to find commonly understood and rounded off values. Parameters computed for spatial zoning of each layer are shown in Table-4. Spatial Zoning Distances (meters) from each feature and corresponding user Preferences (\%) computed from the frequency analysis of response details captured from the field survey are presented in Table 4 to justify the selections. Spatial variation of Population density was carried out for each Grama Niladari Division, by demarcating and computing the land area that could be occupied for dwelling. The separated Landuse layer was reclassified as buildable lands and other land uses namely homestead, built-up area, grassland and rubber were taken as buildable. Population density (persons/ha) in each GND was calculated. During calculations it was considered that public were living only on buildable lands and therefore, the un-buildable lands were classified and masked. Population Density maps were classified using natural breaks in the frequency curve of computed values. The land use layer was reclassified as a group called Waterways consisting of similar land use classes namely Lakes, Canals, Waterhole, Marsh, Sand and Beach areas. Polygons of waterways class which was considered as non buildable area was assigned with zero population (Table-5).

Total buildable area of the project area was approximates $79 \%$. Areas from Waterway features were demarcated as per user preferences to develop the spatial zoning of risk due to waterways. Threat due to built-up nature of properties was developed using the land use layer. Non buildable lands were masked and the rest were classified as in the Table 5. To map risk zones based on land use type other data layers were classified according to spatial zones indicated in Table-5. The GIS model used a qualitative assessment of spatial distributions in each selected layer to carry out a layer aggregation through a spatial overlay 


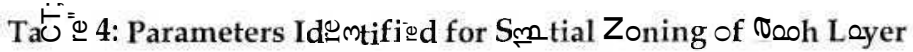

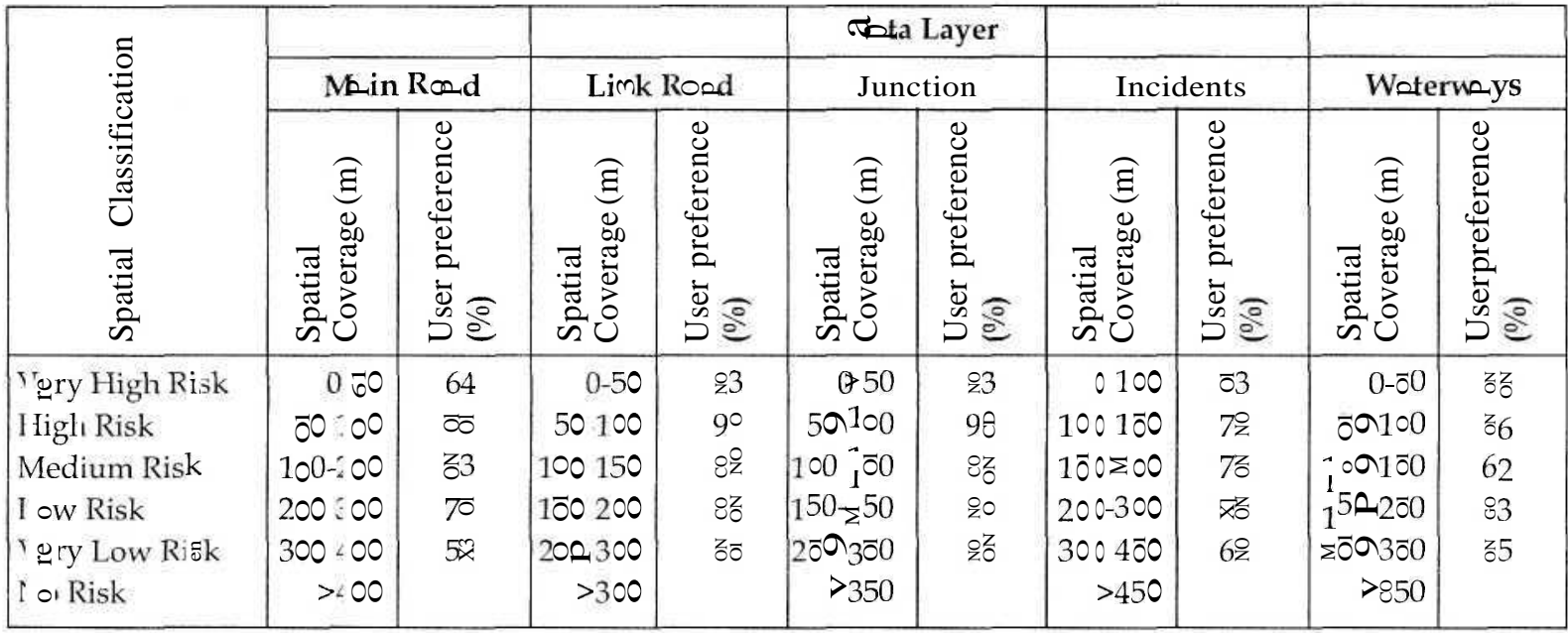

Iob 5: Population and lend us: Iyp

\begin{tabular}{|c|c|c|}
\hline $\begin{array}{c}\text { Spotiol } \\
\text { =lassificatiom }\end{array}$ & $\begin{array}{c}\text { Pomulation } \\
\text { (per }\end{array}$ & Land $u=$ : \\
\hline Very High $\boldsymbol{U}_{\mathbf{s} \text { sk }}$ & $>\bar{x} .92$ & Boilt-up area \\
\hline High Risk & $5.7 z-7.82$ & Homestead \\
\hline Medium Risk & $4.45-\overline{0} .76$ & Erass Hamd \\
\hline Low Risk & $2.60-4.40$ & Pa $\otimes_{y}$ \\
\hline ALow Risk & $\ll 2 . z 0$ & Rubüer \\
\hline -isk & 0 & V at? ways \\
\hline
\end{tabular}

sompection. Si $\times$ cualiti tiva "patia' a gessn 0 to for gach Jayer, mam $l_{y}$ very Hign, High Medism, Lorv, Vift 0 low and $m$ ught, were given $T_{1}, 9,7,5,3$ a as repetitive: voorieal valuos to ic e tify $17, \infty$ w and then 10 corry out a mighted risk indicator issessme it. Weights or $\hat{\theta}_{\text {ac }}$ layer ver $\approx$ a putes is ith

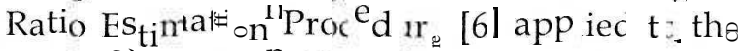

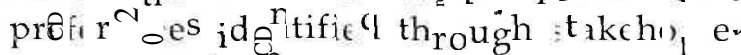
survey. 2isk ir dicatos and $t, 0$ ir spi ia $^{1}$ variibility ${ }_{w} e_{r}^{\theta}$ then $g_{g}$ zat a over ${ }^{\prime \prime}$ th Granta Niladari B omdary tgivi.g assigning weights corrisfc mise to pati i: coverage. Weights for each layer are shown in Table-6

\#) 6: $\quad$ ghts for each layer from user pr ${ }^{\text {efer }}$ onces

\begin{tabular}{|c|c|c|c|}
\hline Lay. $\mathscr{Q}_{\mathrm{r}} \boldsymbol{\sigma e s c r i p t}_{\text {ion }}$ & 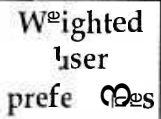 & W@igh & $\begin{array}{c}\% \\
\text { Woights }\end{array}$ \\
\hline Parliament Ro \&d & $\Sigma 30$ & 4.72 & 0.2500 \\
\hline Link Rood & 150 & 3.42 & 0.1847 \\
\hline Junctions & 43 & 1.0 & 0.0030 \\
\hline Population & $\frac{07}{2}$ & 2.26 & $0.11 z^{5}$ \\
\hline Land us@ & 114 & 065 & 0.1404 \\
\hline Waterway\& & 114 & 2. 85 & 0.1404 \\
\hline \multirow[t]{2}{*}{ Previous Insidønt } & 91 & 2.12 & 0.1121 \\
\hline & 609 & 1888 & 1 \\
\hline
\end{tabular}

A ; the spatial risk indiza' ors pertainino to the parliament road is to b: = onpul :d cing 2 Gl, the top priority in case of all users ald $\bar{b}_{2}$ assigned to the parliament road Layer. Thruofh parliament road layer was not listed in the usir. prof:rens: list to alaulat: $w$ ights to be assigned, user preferences for Parliament road layer zoning were sought in the questionnair?. User preference of secu $\mathrm{r}^{\mathrm{ity}}$ optio ${ }_{\mathrm{S}} \mathrm{W}$ th conceptual command zone for eath sqou ty arrangement (Table-7) we e incorporated as three separate shape files coln ${ }^{3}$ ned to indicate a probable management option

\subsection{Result}

Computed risk status Indieat ${ }^{\circ} \mathrm{rs}$ :or ${ }^{\circ}$. Project

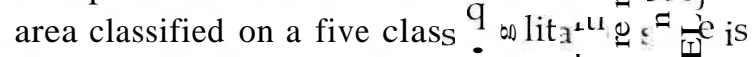
shown in the Figure-4. The risk $i_{1} \iota_{i}{ }_{0}{ }_{0}{ }^{\circ} o_{r s}{ }_{w}$ ere classified according to natum $\mathrm{b}^{\mathrm{b}} \cdot \mathrm{Nk}_{\mathrm{s}} \mathrm{h}_{\mathrm{at}} \mathrm{w}_{\text {we }}$ in the frequency curve of values $s^{2} c_{2}$ Thip summary details pertaining to $x t e n t s ~ U n d e r$ each class is shown in Table 8.

Table 7: Distance zoning incorporated for Security Arrangement

\begin{tabular}{|c|c|c|c|c|c|}
\hline \multirow[b]{2}{*}{ 工ур: } & \multicolumn{5}{|c|}{ Spatial zones (meters) } \\
\hline & $\mathrm{V} \Xi$ & 포 & $\sim$ & $\mathrm{L}$ & VL \\
\hline $\begin{array}{l}\text { Group Sesurity } \\
\text { of } 3 \text { per Group }\end{array}$ & 100 & 150 & 200 & 258 & 300 \\
\hline $\begin{array}{l}\text { Stationary } \\
\text { Sentry (Single } \\
\text { person) }\end{array}$ & $\sigma_{0}$ & $10^{0}$ & 100 & 280 & 200 \\
\hline $\begin{array}{l}\text { Mobile Patrol } \\
4 \text { Person/ } \\
\text { ve } \amalg \text { icle }\end{array}$ & - & - & 3000 & - & - \\
\hline
\end{tabular}




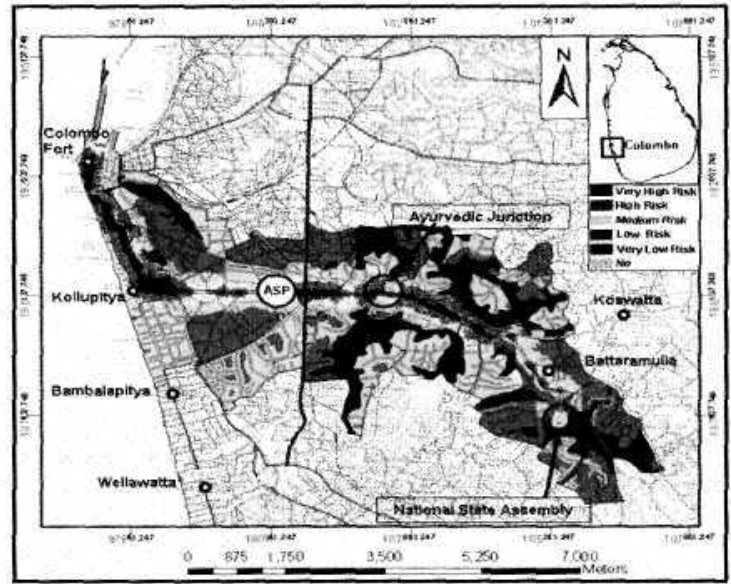

Figure 4: Overall Risk Status Indicators for the Study Area

Table 8: Risk Status Indicator and Spatial Extents

\begin{tabular}{|c|c|}
\hline Risk Status Indicator & Area $(\mathrm{Ha})$ \\
\hline VH & 113.40 \\
H & 215.86 \\
M & 320.40 \\
L & 1002.83 \\
VL & 953.96 \\
No & 614.99 \\
Total & 3221.44 \\
\hline
\end{tabular}

Security deployments were carried out manually with initial placement of grouped sentry to cover High and Very High risk regions and then single person stationary sentries were placed to fill gaps which were spatially distributed. Four mobile patrol cars were placed along the parliament road to support the security of surrounding vicinity along byroads. The security mobilization in the area is shown in Table-9. A Management Option which proposed a trial security arrangement was developed as three GIS layers having spatially varying security zoning. The three layers were given equal weights and were overlaid to combine as the overall security indicator layer. The overall security indicator layer was then reclassified to three qualitative security indicator groups as Very High, High, and Moderate. the aforesaid security status Indicator for The mentioned management option is shown in Figure 5.

Proposed Security Indicator Layer was then overlaid with the Overall Risk Status Indicator layer to assess the spatial distribution of the secured status for the proposed security deployment. The results from overlay operation was classified to a three class "secure" status classes as Secure, Moderately secure, and
Table 9: Security Deployment for Propose Management Option

\begin{tabular}{|cl|c|}
\hline Type of Security & No of Units \\
\hline 1 & Group Sentry & 201 \\
2 & Stationary Sentry & 387 \\
3 & Mobile Patrol & 04 \\
\hline
\end{tabular}

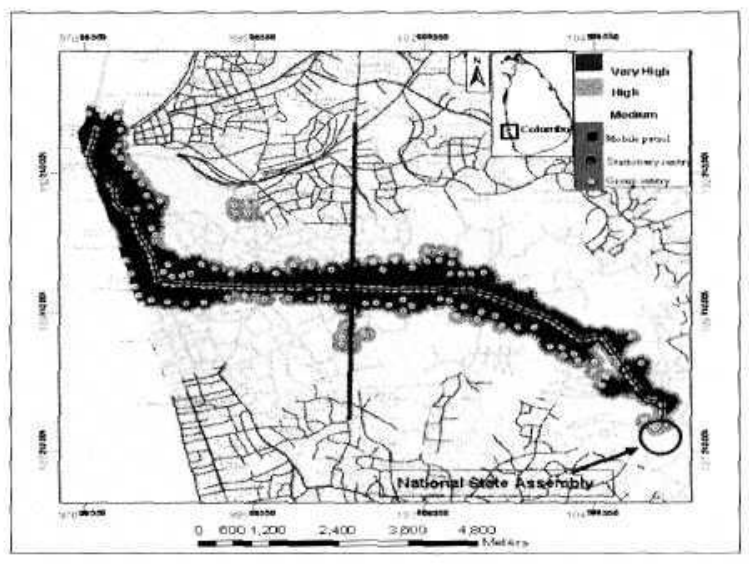

Figure $5:$ Arrangement of Secuity and Spatial Distribution of overall security indicator for the study area

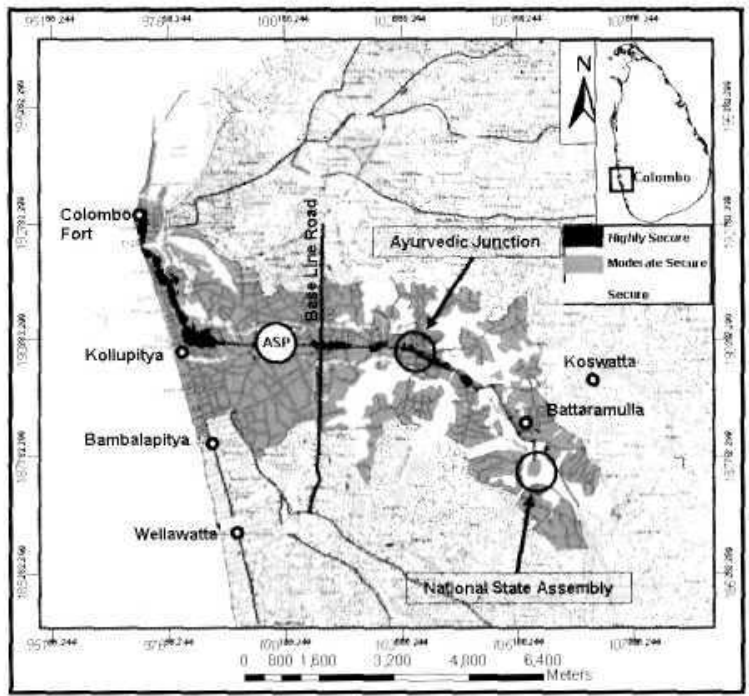

Figure 6 : Security Status Distribution after Security Mobilization

Highly secure. Figure 6 shows the spatial variation and Table 10 indicates the spatial coverage by each zone.

The spatial matching of risk status indicator and the security status layer through an overlay operation was based on a simple matrix assessment which classified the 5 class risk status indicators to arrive at the new classification of secure status with three classes (Table 11)

Overall Risk Status indicator and the secure status indicators after the management option were spatially aggregated to Grama Niladhari Divisions and the results are shown in Figure 7 
Table 10 Spatial Coverage of Secure Regions in Project Area.

\begin{tabular}{|l|c|}
\hline Secure status Indicator & Spatial extent (Ha) \\
\hline Highly Secure & 810.17 \\
Moderately Secure & 2294.09 \\
Secure & 117.19 \\
\hline
\end{tabular}

Table 11: Risk and Security Status Indicator Spatial Overlay and reclassification
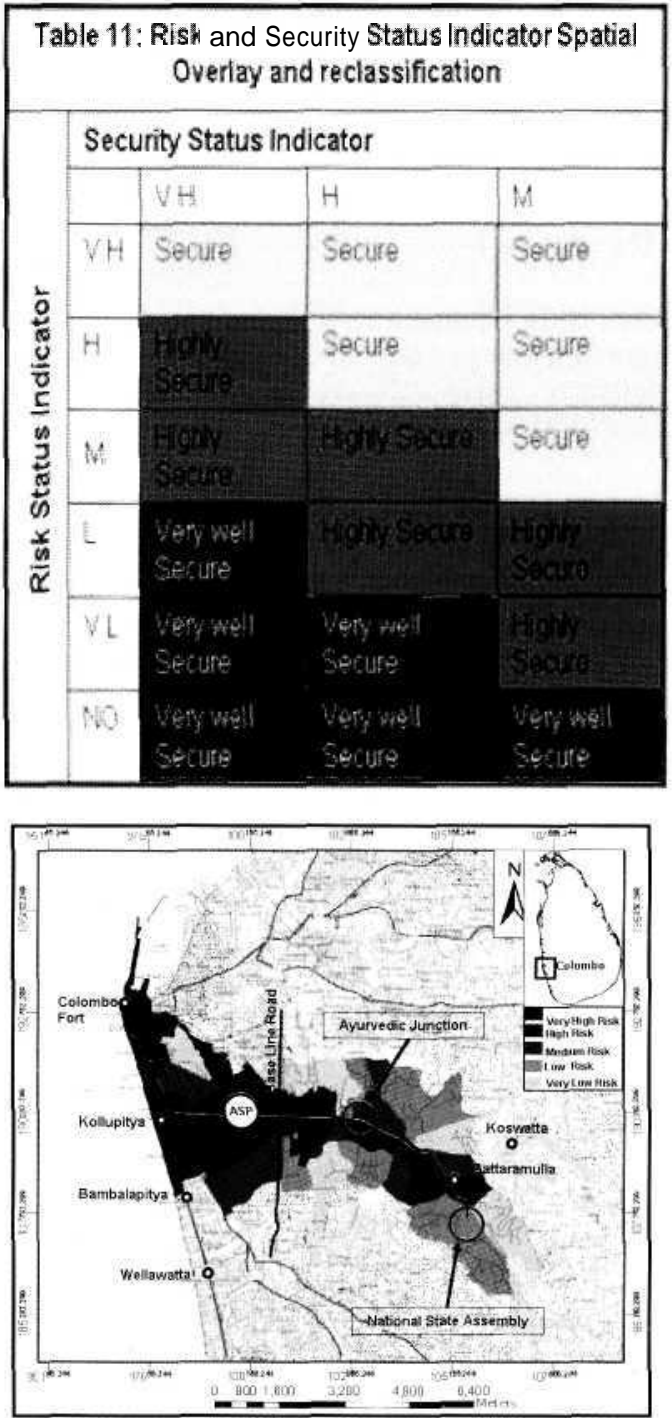

Figure 7: Overall Risks status arranged to GN Division boundary

and Figure 8. The indicators were classified- as five and three qualitative groups according to Natural breaks in the frequencies of occurrences. This spatial aggregation enables managers to identify status of the area and then to mobilize resources accordingly.

\subsection{Discussion}

The case study showed systematic analyses of the risk status and the incorporation of security

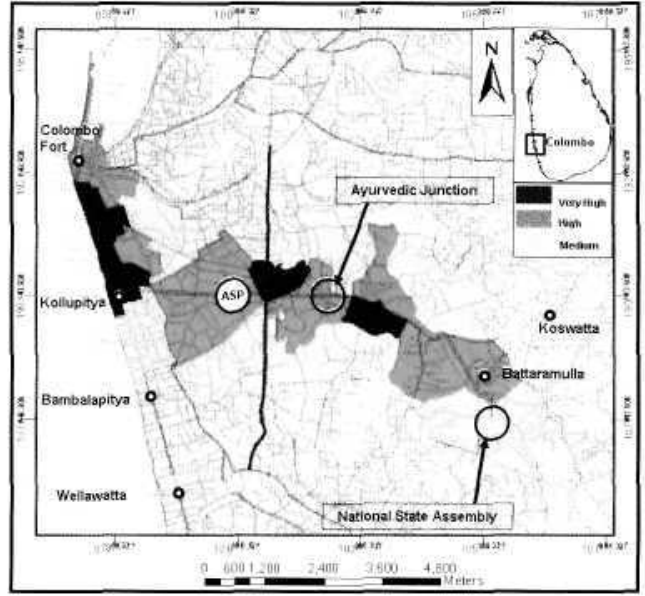

Figure 8: Aggregate Secure Status Indicatorfor GNDivisions

using GIS as a tool. The simple conceptual GIS model used in the study enabled the computation of status indicators to visualize the pattern of variations in space. The model shows strengthof GIS to carryout easy incorporation of various spatially distributed management options with relative ease.

The sample size used for the user surveys were only 29. This sample of 29 for an approximate population of 600,000 at $95 \%$ confidence limit provides a confidence interval of approximately $20 \%$. Therefore, for detailed applications it may be necessary to perform calculations with larger samples. [1, 2]

Spatial zoning different data layers are subjective. The study used a survey questionnaire to identify spatial zoning preferred by various stakeholders and then incorporated statistical indicators to arrive at suitable distance ranges for geographic distributions. Spatial zoning of security Indicators was carried out with judgmental values and these needs to be carefully ascertained and strengthened for actual applications. Incase of actual applications, the systematic approach of this study may be adopted with parameter strengthening through wider user community surveys.

Statistics derived from the spatial analysis indicates the potential and value of aggregating the GIS results for management of resources or planning of similar activities. Results would enable the mobilizations either on the basis of smaller land parcels based on uniform status ranks or on the basis of administrative divisions 
which have spatially averaged status rankings. The casestudy applications indicated the methodology of applying GIS concepts to various points, line or polygon data sets, carrying out of spatial zoning an overlay operation, thereby presenting an example of systematic procedure for similar GIS undertakings. The casestudy also indicates the potential of GIS to easily incorporate concept changes through a change of data layers or change of spatial data arrangements. In case a manager requires to modify a security arrangement then it is necessary to incorporate the change to the respective security data layer, overlay with other security data layers and then finally combine with the risk status indicator to make an assessment to identify the adequacy of proposal. On the other hand, if the modification suggested is not final, then a separate layer could be added only for the change and then overlaid with the available final to identify whether the change had provided the desired result. A manger can use either of the options based on a given situation. Such manipulation capabilities will add to the strengths of a resourcemanager.

Spatial aggregation capability of GIS enables a manager to compute weighted averages based on the effected spatial extents. This is a very effective tool in GIS for rational management of resources.

\subsection{Conclusions}

1.0 The potential of GIS for risk and security assessment of spatial extents which are at close proximity to important infrastructure was successfully showed through a case studyapplication.

2.0 The study presented a systematic methodology to use a simple GIS model with appropriate stakeholder input for parameter strengthening.

3.0 Results of the case study application showed the pattern of risk and security options that are much needed by resource planners and managers.

4.0 Effectiveness of spatial aggregation in GIS by the incorporation of weights based on influence area was shown through the case study.
5.0 The model used for the present work can be easily used as effective tool for similar studies.

\subsection{Acknowledgments}

The authors wish to extend sincere appreciation of the encouragement given by the management and the staff of Ministry of Defence, and the Centre for Research and Development to publish this work. Support of the ICGAT of University of Moratuwa and its staff is gratefully acknowledged.

\subsection{References}

1.0 CRS 2007 Creative Research Systems, Sample Size Calculator, 411 B Street Suite 2, Petaluma CA 94952, http://www.surveysystem.com/ sscalc.htm\#one, Visited on January 2007

2.0 Custom Insight 2007, CustomInsight, Survey Tips - Random Sample Calculator, 750 Arrowhead Dr, Carson City, NV 89706, USA http:// www.custominsight.com/articles/randomsample-calculator.asp, Visited on January 2007

3.0 GIS for Homeland Security An ESRI"White Paper. November 2001 http://www.esti.com/ library/whitpapers /pdfs / homelandsecurity_wp.pdf, Visited, 5th May 2008.

4.0 Lo, C.P., Yeung, A.K.W.,Concepts and Techniques of Geographic Information Sytems, Prenice-Hall of India, 2005

5.0 Longlel, P.A., Goodchild, M.F., Maguire, D.J., Rhind, D.W., Geographic Information System and Science, John Wiley \& Sons Ltd, 2002

6.0 Malczewski, \}., GIS and Multicriteria Decision Analysis, Department of Geography, University of Western Ontario, 1999,pp 177 -189.

7.0 OSHA- Occupational Safety \& Health Administration, "Emergency Preparedness-Fire and Explosion Planning Matrix", 200, Constitution Avenue, NW, Washington DC 20210, 2008, http://www.osha.gov/dep/fiveexpma trix/index.

8.0 Risk Management: An Essential Guide to Protecting Critical Assets www.iwar.org.uk/ comsec/resources/risk/ risk-mgmt.pdf, Visted, 1st January 2008

9.0 Tan, W., Practical Research Methods, 2nd Ed., Prince Hall, 2004

10.0USDJ- 2005 US Department of Justice, "Assessing and Managing the Terrorism Threat", NCJ 210680 Office of Justice Programs, Bureau of Justice Assistance, 810, Seventh Street NW., Washington DC 20531., September 2005 